\title{
Maternal-Newborn Bonding Concept Analysis
}

Jayne Barker ${ }^{1}$, Adrienne Daniels ${ }^{1}$, Kymberly $\mathrm{O}^{\prime} \mathrm{Neal}^{1}$ and Sharon L. Van Sell ${ }^{*}$

${ }^{1}$ Graduate Nursing Program, Texas Woman's University, USA

${ }^{2}$ Professor, The Houston J. and Florence A. Doswell College of Nursing, Texas Woman's University, USA

\begin{abstract}
Maternal-newborn bonding is the complex process of attachment between a mother and newborn. The authors used the Walker and Avant methodology to conduct a concept analysis regarding maternalnewborn bonding as it relates to advanced practice nurse (APN), the patient, and health care. The attributes of maternal-newborn bonding include affection, association, attachment, and relationship. The consequences of maternal-newborn bonding include love, trust, protection, and maternal-child relationship. The APN must be able to recognize and understand the importance of maternal-newborn bonding to have anoptimal outcome for the patient. A model case, borderline case, and contrary case were discussed to provide an example of the maternal-newborn bonding concept. Discussion regarding empirical referents is also included.
\end{abstract}

\section{Description of Concept}

Maternal-newborn bonding is a concept used throughout the obstetrical and pediatric fields, but not widely known amongst all clinicians. The connection made after birth directly affects both the mother and newborn physiologically, psychologically and emotionally. A strong bond formed between a mother and infant leads to positive outcomes and impacts the maternal child relationship through the lifespan. "The parent-infant bond provides a foundation for future adaptation, relationships, and mental health for children and adults" (p. 246) [1]. Difficulty forming a bond could lead to detrimental problems for the mother, child, society and the healthcare system.

The maternal-newborn bond directly influences the healthcare system in a variety of ways. The initial bond that occurs between the mother and child after delivery can play a fundamental role in many physiological and psychological aspects. Physiological or psychological instability could potentially lead to a prolonged length of stay, a higher level of care and increased medical costs. A positive bond leads to a positive home life and good health. Good health could be directly related the mother providing basic needs and medical care for the child. As a result, the children have improved health, a decreased number of medical visits and decreased medical care costs throughout the lifespan. Inversely, a study described a situation of impaired maternal-newborn attachment, a bonding disorder can occur [2]. The impaired bond could lead to a decline in basic needs of the child being met and decrease in necessary medical care needed for healthy growth and development.

The concept of maternal-newborn bonding also directly influences advanced practice nurses (APN). Understanding the concept can give the APN an inside view of the relationship that the mother and child have whether positive or negative. A positive maternal-newborn bond detected by the APN provides assurance that needs of the newborn are being met. The APN plays a vital role in the detection of an impaired connection between mother and child and is responsible for determining the appropriate care path to improve the bond.

As nurses that work in the maternal, newborn, and pediatric fields, maternal-newborn bonding is a concept frequently used. In practice, we have found that bonding plays a significant role in positive maternal and newborn outcome; whether in the immediate postdelivery phase or years down the road. The analysis of the concept maternal-newborn bonding was performed to further explain the importance of a strong familial bond on the health and development of a child and mother. As future APNs in the maternal and pediatric specialties, we hope to use the information in our practice to create a better family dynamic and truly improve society.

\section{Aims and Purpose}

Walker and Avant [3] stated "this second step helps focus attention on exactly what use you intend to make of the results of your effort" (p.161). The concept of maternal-newborn bonding had been extensively studied and discussed throughout the years. The aims and purpose of the concept analysis are to define the concept maternalnewborn bonding and present the findings of the extensive research completed.

\section{Theory Relates to Practice}

Walker and Avant [3] stated, "The purpose of science is to develop knowledge. That knowledge is often summarized or synthesized into a theory. Theories guide both research and practice" (p.40). Consequently, every medical discipline has tried to define and correlate theory to patient care. In the case of nursing, the concept of maternal-newborn bonding is both challenging and rewarding.

Maternal-newborn bonding is a complex phenomenon that occurs during a very significant time for the mother and her infant [4]. The bond is a vital process, which begins in early infancy and continues over theyears. The importance of maternal-newborn bonding should be emphasized to all mothers when a pregnancy is planned. Due to the importance of the maternal-newborn bond, the APN and other disciplines need to be able to recognize when an intervention is necessary to achieve and improve the bonding process. To help facilitate the maternal-newborn bond, the APN and staff nurses can encourage skin-to-skin, breastfeeding, eye contact, encouraging contact between mother and newborn, and promoting a positive environment.

"Corresponding Author: Prof. Sharon L. Van Sell, The Houston J. and Florence A. Doswell College of Nursing, 5500 Southwestern Medical Avenue, \#7209, Dallas, Texas, USA, 75235-7299, Tel: 1-864-275-3527, FAX: 214-689-6539; E-mail: svansell@twu.edu

Citation: Barker J, Daniels A, O’Neal K, Van Sell SL (2017) Maternal-Newborn Bonding Concept Analysis. Int J Nurs Clin Pract 4: 229. doi: https://doi. org/10.15344/2394-4978/2017/229

Copyright: (c) 2017 Barker et al. This is an open-access article distributed under the terms of the Creative Commons Attribution License, which permits unrestricted use, distribution, and reproduction in any medium, provided the original author and source are credited. 
Citation: Barker J, Daniels A, O’Neal K, Van Sell SL (2017) Maternal-Newborn Bonding Concept Analysis. Int J Nurs Clin Pract 4: 229. doi: https://doi. org/10.15344/2394-4978/2017/229

Page 2 of 6

\section{Defining the Concept}

The exact concept of maternal-newborn bonding, could not be directly found through research and literature review; however, the associated term bonding could be used to develop the concept under analysis and provide the most accurate definition. The MerriamWebster Online Dictionary defined bonding as "the formation of a close relationship (as between a mother and child or between a person and an animal) especially through frequent or constant association; the attaching of a material (as porcelain) to a tooth surface especially for cosmetic purposes" [5]. The MacMillan Dictionary further added to the definition and described bonding as "the development of a special close relationship between people; in chemistry, the process by which atoms join together" [6]. Small Business Encyclopedia described another definition of bonding within the business fieldas "a guarantee of performance required, either by law or consumer demand, for many businesses, most typically general contractors, temporary personnel agencies, janitorial companies and businesses with government contracts" [7]. Finally, Dictionary.com defined bonding as

a psychology, animal behavior: a relationship that usually begins at the time of birth between a parent and offspring and that establishes the basis for an ongoing mutual attachment; the establishment of a pair bond; a close friendship that develops between adults, often as a result of intense experiences, as those shared in military combat; dentistry: a technique or procedure for restoring the discolored or damaged surface of a tooth by coating it with a highly durable resinous material that adheres to the existing enamel" [8].

The definitions of bonding were broad and encompassed many different disciplines including chemistry, dentistry, sociology, biology, and business.

When viewing the concept from a nursing perspective, definitions are more specific and involve the connection between a mother and child. In a study conducted to determine effects of depression on maternal-newborn attachment, Ohoka et al. [2] described bonding as "the process of developing a relationship and attachment between mother and newborn child" (p. 631). Swain et al. [9] used the term parenting to describe the connection between mother and child. In the study to determine the biological factors that occur during attachment, parenting was explained as "meeting the primal evolutionary needs for survival and continuation of our species, parenting involves interrelated biological, psychological, and behavioral caregiving mechanisms that contribute critically to the first environment the child experiences as a new family member" (p. 79) [9]. Additionally, Numan and Young [10] performed a study related to neural mechanisms and the effects on maternal-infant bonding. Numan and Young [10] described a more specific connection between a mother and child being that "the mother-infant bond, therefore, is the most common enduring social bond in mammals" (p. 99). The research also explained that the mother-infant connection is the strongest relationship bond and can influence other social bonds [10].

For the purpose of this concept analysis, the focus was on the definitions of bonding directly related to the connection between a mother and child. The definition of the concept maternal-newborn bonding, as it relates to advanced practice nursing, includes the accumulation of all the related definitions and can further describe the connection that occurs between a mother and newborn the first time meeting and in the future.

\section{Attributes}

After thoroughly examining the research, many attributes were found to define maternal-newborn bonding. According to Walker and Avant [3] "defining the attributes of the concept is the heart of concept analysis" (p. 162). The key attributes identified are affection, association, attachment, and relationship.

According to Merriam-Webster Online Dictionary, the definition of affection is "a feeling of liking and caring for someone or something, feelings of love, a moderate feeling or emotion, a tender attachment" [11]. Affection between the mother and the newborn is an important characteristic in the process of bonding because it displays the emotions between the mother and newborn.

Merriam-Webster Online Dictionary's definition of association was "a connection between people or a feeling or memory connected to that person"[12]. Oxford Dictionary stated the origin of the term association comes from mid 16th century from Medieval Latin Association: "to unite, ally" [13]. The association between the mother and newborn must occur for the bonding to transpire. The mother and child must "unite" together and form a bond.

Merriam-Webster Online Dictionary defined the term relationship as "the way in which two or more people behave toward each other and the way in which two or more people are connected" [14]. A more thorough definition is "the relation connecting or binding participants in a relationship; kinship, a specific instance or type of kinship; a state of affairs existing between those having relations or dealings" [14]. The mother and newborn become connected in an intimate relationship in the first hours of the infant's life.

Finally, the most important attribute, attachment, is defined in the Cambridge Dictionary as "a strong feeling of being emotionally close to someone or something" [15]. According to Diane Benoit [16] "attachment is one specific aspect of the relationship between a child and a parent with its purpose being to make a child safe, secure and protected"(p. 541).

\section{Antecedents and Consequences}

"Antecedents are those events or incidents that must occur or be in place prior to the occurrence of the concept" (p.167) [3]. MerriamWebster's Online Dictionary defined antecedent as "something that came from else and may have influenced or caused it" [17]. Both antecedents and consequences are helpful in refining the attributes further [3]. Cambridge English Dictionary defined antecedent as "something existing or happening before, especially as the cause of an event or situation" [18]. Antecedents relevant to maternal-newborn bonding are birth, two people, touch, breastfeeding, eye contact, and vocal tone.

A crucial antecedent to maternal-newborn bonding is the actual birth of the newborn in which two people are present. According to the definition of bonding from the MacMillan Dictionary, "the development of a special close relationship between people," it is essential for more than one person to be present for bonding to occur [6].

Another important antecedent is touch. Touch includes skin-toskin contact such as the unclothed newborn lying on mother's bare chest or the mother stroking the newborn's hairs, kissing the cheek 
or head, holding hands, etc. Skin-to-skin contact is also known as kangaroo care. Conde-Agudelo and Díaz-Rossello [19] revealed growing evidence that indicated kangaroo care could cause an increase in maternal-infant attachment. The term attachment is an attribute of bonding and sometimes used interchangeably. Phillips [20] stated, "hormones known to influence attachment behaviors are increased by skin-to-skin contact" (p. 68). Phillips [20] focused on the first hour after birth, which was referred to as "the sacred hour" (p. 67). Particular emphasis was on the hormone oxytocin, which was shown to "increase relaxation, attraction, facial recognition, and maternal care-giving behaviors" (p. 68) [20]. All of these are supportive in the bonding process.

Breast feeding is a very intimate and private act between a mother and a newborn. Breastfeeding is an antecedent because of the closeness and connection. Breast feeding significantly enhances the opportunity of a bond forming between the mother and infant. Zetterstrom [21] stated that infant suckling stimulates the "release of maternal oxytocin, which causes milk ejection and promotes the development of maternal behaviour and mother-infant bonding" (p. 5).

Eye contact between mother and newborn is an antecedent of maternal-newborn bonding. As discussed in an article by Kenneth S. Robson, eye contact played a key role in the emotions of the mother during the postpartum period:

One aspect of a longitudinal study in which the author is participating involves rather extensive post-natal interviews with fifty-four primiparous mothers. Most of these women describe some initial feelings of "strangeness", "distance" and unfamiliarity towards their offspring. which persist for at least the first few weeks of life.When one inquires as to when the mother first felt love, when she ceased feeling "strange" with her child and when he "became a person" to her, the answer to these questions frequently involves the baby's "looking", as if recognizing objects in the environment. A small number specifically articulate that eye-to-eye contact releases strong positive feelings. These feelings have something to do with "being recognized" in a highly personal and intimate way (p. 16). [22].

Maternal-newborn bonding would be encouraged when the mother speaks to the infant in a soft, soothing tone. DeCasper and Fifer [23] described that a newborn could discriminate between different recorded female voices and showed a preference for his or her mother's voice. A preference for the mother's voice would certainly heighten the bonding development.

Consequences of the concept maternal-newborn bonding are the "events or incidents that occur as a result of the occurrence of the concept" (p. 167) [3]. The consequences identified for the concept of maternal-newborn bonding are security and protection, love, trusting relationship and prolonged breastfeeding. When the newborn has bonded with the mother, the newborn develops a sense of security and protection. A trusting relationship has formed. The newborn now relies completely on the mother to fill all of the basic needs.

Prolonged breastfeeding is a consequence of the maternal-newborn bond. According to Cernadas, Noceda, Barrera, Martinez, and Garsd [24] mothers "with very good bonding, the duration of exclusive breastfeeding was significantly longer than the mothers with good bonding" (p. 141).Another consequence of the concept maternalnewborn bonding is love. The mother and infant have formed a bond and now share unconditional love between the two of them.

\section{Model Case}

Walker and Avant [3] stated, "A model case is an example of the use of the concept that demonstrates all the defining attributes to the concept" (p.163). Mrs. P is a 35-year-old pregnant woman, who married her high school sweetheart tenyears ago. The happy couple is excited to finally be expecting their first child after trying for quite some time. Mrs. P arrives at the hospital for a scheduled induction. Once the patient was settled, she and her husband began to talk about how they can't wait to see the baby, and they wonder who she will resemble. Mrs. P labor progressed quickly, and soon she delivered a healthy baby girl. The nurse placed the baby on Mrs. P for skin-toskin contact. Mrs. P smiled and kissed the baby on the cheek when positioning the baby on her chest. During skin-to-skin contact, the nurse assisted Mrs. P with breastfeeding. The baby began to fuss while attempting to breastfeeding. Mrs. P talked softly to the baby in attempts to soothe her. During the hospital stay, Mrs. P was very attentive to the baby's needs. As the nurses rounded, they would always find Mrs. P having some interaction with the baby.

\section{Borderline Case}

Borderline cases are "those examples or instances that contain most of the defining attributes of the concept being examined but not all of them" (p.164) [3]. The borderline case presented here is of Mrs. A, who is a 38 years old pregnant with her first child. Mrs. A had been having some headaches and occasional dizziness the past couple of weeks but has contributed to things being stressful at work. Today Mrs. A presented to her obstetrical/gynecologist for her routine 30week appointment. At the doctor's office, her blood pressure showed high values, even with three different readings, and she informed the doctor of her symptoms for the past few weeks. The doctor sent Mrs. A to the hospital for admission to labor and delivery for further testing/monitoring. Upon admission, all findings show preeclampsia. Mrs. A is started on magnesium sulfate intravenously. Mrs. A soon delivers a baby boy. Mrs. A is able to briefly see her and hold her infant before he is transferred to the neonatal intensive care unit. While Mrs. A remains in labor and delivery on magnesium sulfate, she can call the nurses calling for her baby to get an update. This case shows some attributes but not all. For example, Mrs. A was not able to have extensive skin to skin time with her baby at the time of birth.

\section{Contrary Case}

According to Walker and Avant [3], a contrary case is an example that does not represent the concept and contains any of the defining attributes. Ms. R is a 31-year-old female presents to the emergency room complaining of severe abdominal and back pain. She has an adverse medical history and denies being pregnant, but is unable to recall last menstrual cycle. Hcg test confirms pregnancy. Ms. R was taken to radiology for an ultrasound to determine the weeks of the fetus. The ultrasound confirms she is $36 / 4$ weeks. She is transferred to labor and delivered to continue monitoring. She delivers a baby girl the next day. The patient does not want the infant on her chest and refuses to hold her newborn. The patient refused to have the infant to be in the room with her. The infant transferredtoneonatal intensive care unit for boarding. Further discussion with the mom, she expresses her desire for the infant to be placed for adoption. Notifications to Child protective services were madefor anadoptive plan to be put in place.

In this contrary case, it is clear that none of the defining attributes are presents. Contrary cases, however, can be very useful in the 
analysis since it is often easier to say what something "is not" than what something "is" [3].

\section{Empirical Referents}

Empirical referents are described as "the means by which you can recognize or measure the defining characteristics or attributes" (p. 168) [3]. Empirical referents are not tools to measure the concept. The empirical referents identified for the conceptof maternal-newborn bonding are affectionate acts including hugging, kissing, skin-to-skin contact, and breastfeeding. A mother-to-infant bonding scale was designed to assess the mother's feelings towards her new baby. The scale consisted of 8 questions, and the mother should take it during the first three days after she delivers the baby [25].

\section{Impact on Advanced Nursing Practice}

The concept of maternal-newborn bonding has an impact on present day advanced nursing practice. The APN plays a key role in promoting a positive maternal-newborn bond. The APN knows that bonding improves the newborn's physiological state and maternal emotional state. One technique the APN should use to promote bonding is kangaroo care and skin to skin immediately after birth through newborn phase. A study was conducted to determine the effects of kangaroo care on the infant and mother. Kangaroo care was shown to stabilize infant breathing, improve maternal-infant attachment, and reduce maternal stress [26]. Kangaroo care is an inexpensive, easy task, which can potentially prevent prolonged hospital stay and decrease medical care costs.

In addition to kangaroo care and skin to skin, the APN is also responsible for promoting breastfeeding. A breastfeeding mother provides the infant with basic needs of eating, but also helps promote a strong emotional maternal-newborn bond. According to the American Academy of Pediatrics [27], breastfeeding decreases infant risk of developing many common illnesses and childhood obesity, as well as decreasing maternal postpartum bleeding and risk for developing certain cancers later in life. The health benefits of breastfeeding could ultimately reduce the number of medical visits, lower healthcare costs, and improve the health of society as a whole.

The APN is responsible for promoting improved maternalnewborn bonding practices but also recognizing an impaired bond. An impaired bond requires a plan of action developed by the APN and family to make improvements. According to Wan et al. [28], visualization after the birth of the infant impacted bonding and showed parental responsiveness or lack of emotional closeness with the infant. An APN working with a family directly after birth has the opportunity to observe signs of impaired bonding and begin assistance in promoting a positive bond. The APN must understand that "consistent attachments are crucial for the formation of close bonds to the infant" (p. 932) [29].

The development of a child is particularly important to an APN working in the pediatric specialty. The maternal-newborn bond plays a key role in a child's development, and the APN must be aware of the impact it could potentially have on the child. According to Spratt et al. [1] during the early phase of childhood, brain development was shown to be susceptible to environmental influences and nurturing care. Another study conducted by Dubber, Reck, Muller, and Gawlik [30], showed a link between emotional disorders in childhood and impaired maternal bonding. The research provides the APN with a background of potential causes of brain and emotional development about impaired maternal-newborn bonding.

The concept of maternal-newborn bonding is of extreme importance to the APN working in a maternal, newborn, or pediatric setting. The APN is responsible for providing care to the family and promoting improved health practices. An APN must be able to recognize positive or impaired bonding between a mother and child and create a plan of care, absent of judgment, to improve the family dynamic. Kinsey, Baptiste-Roberts, Zhu, and Kjerulff [31], described that everyday life stressors had an impact on bonding and the clinicians, including APNs, have a responsibility to provide support. Similarly, Zanardo et al. [32] instructed that clinicians must be aware of life stressors in the peripartum period that could influence the maternal-newborn bond, and be prepared to provide interventions to improve health for the entire family. The APN should continue to work with the family as one unit and follow-up to ensure the improved health of all members.

\section{Impact on Nursing Research}

The concept of maternal-newborn bonding plays a role in present and future nursing research. A thorough literature review was conductedand the information gathered was useful for healthcare workers that are in contact with the maternal-newborn demographic. An abundance of information showed the effect of active or impaired bonding on children and mothers throughout the lifespan. Despite the vast amount of research conducted related to the maternal-newborn bonding concept, further research could prove useful when caring for these patients.

Nursing research is lacking in certain areas pertaining to the maternal-newborn bonding concept. Further research explaining the influence of an impaired maternal-newborn bond and risk of child abuse or neglect would be beneficial. Current research lacked in providing a clear understanding of the potential risk for abuse or neglect. Dubber et al. [30] concluded that a negative maternalnewborn bond had a significant impact on maternal depression and emotional health. Maternal depression or alteration in emotional health correlates in some cases with child abuse or neglect. A conclusion could be that a negative maternal-newborn bond could increase the risk for child abuse or neglect. In the healthcare field, future studies could provide useful information in determining children at risk for abuse and neglect and earlier interventions to be made to prevent the behavior.

Another impact the maternal-newborn bonding concept made on nursing research involved the discovery of inconsistency among research methods. Kinsey et al. [31] described the need for nursing researchers to develop a way for bonding to be measured. Throughout the research, there was shown to be different methods of bonding measurement used to determine the impact on mother and child including maternal questionnaires, physiological data, and behavioral status of the mother and child. A global measurement tool that can be utilized by researchers and clinicians would be beneficial to determine bonding quality and need for medical or psychological interventions if necessary.

\section{Concept Model}

The maternal-newborn bonding concept model in Figure 1 depicts the effects a strong bond has on the mother-child relationship. As the mother and child connect to one another, the bond between them 
Citation: Barker J, Daniels A, O’Neal K, Van Sell SL (2017) Maternal-Newborn Bonding Concept Analysis. Int J Nurs Clin Pract 4: 229. doi: https://doi. org/10.15344/2394-4978/2017/229

Page 5 of 6

grows. The bond in this concept model is represented as a heart to illustrate that the bond between mother and child involves emotion and caring. During the development of the bond, the mother and child individually show systemic stabilization. Once a maternal-newborn bond is made, four significant consequences occur. The results include trust, love, protection and prolonged breastfeeding. The consequences of the strongbond encompass the mother and infant. The arrow from the bond to the consequences, illustrate how the bond between mother and infant influences the level of trust, love, protection and prolonged breastfeeding. Similarly, the arrow from the consequences to the bond, show that level of trust, love, protection and prolonged breastfeeding impact the strength of the maternal-newborn bond The maternal-newborn bonding concept model provides a pictorial description of the importance of a strong bond and the impact on many aspects of the mother and child's lives.
5. Bonding (2016) In Merriam-Webster's Online Dictionary
6. Bonding (2016) In MacMillan Dictionary.
7. Bonding (2016) In Small Business Encyclopedia.
8. Bonding (2016) In Dictionary.com.

9. Swain JE, Kim P, Spicer J, et al. (2014) Approaching the biology of human parental attachment: Brain imaging, oxytocin and coordinated assessments of mothers and fathers. Brain Res 1580: 78-101.

10. Numan M, Young LJ (2016) Neural mechanisms of mother-infant bonding and pair bonding: Similarities, differences, and broader implications. Horm Behav 77: 98-112.

11. Affection (2016) In Merriam-Webster's Online Dictionary.

12. Association (2016) In Merriam-Webster's Online Dictionary.

\section{Competing Interests}

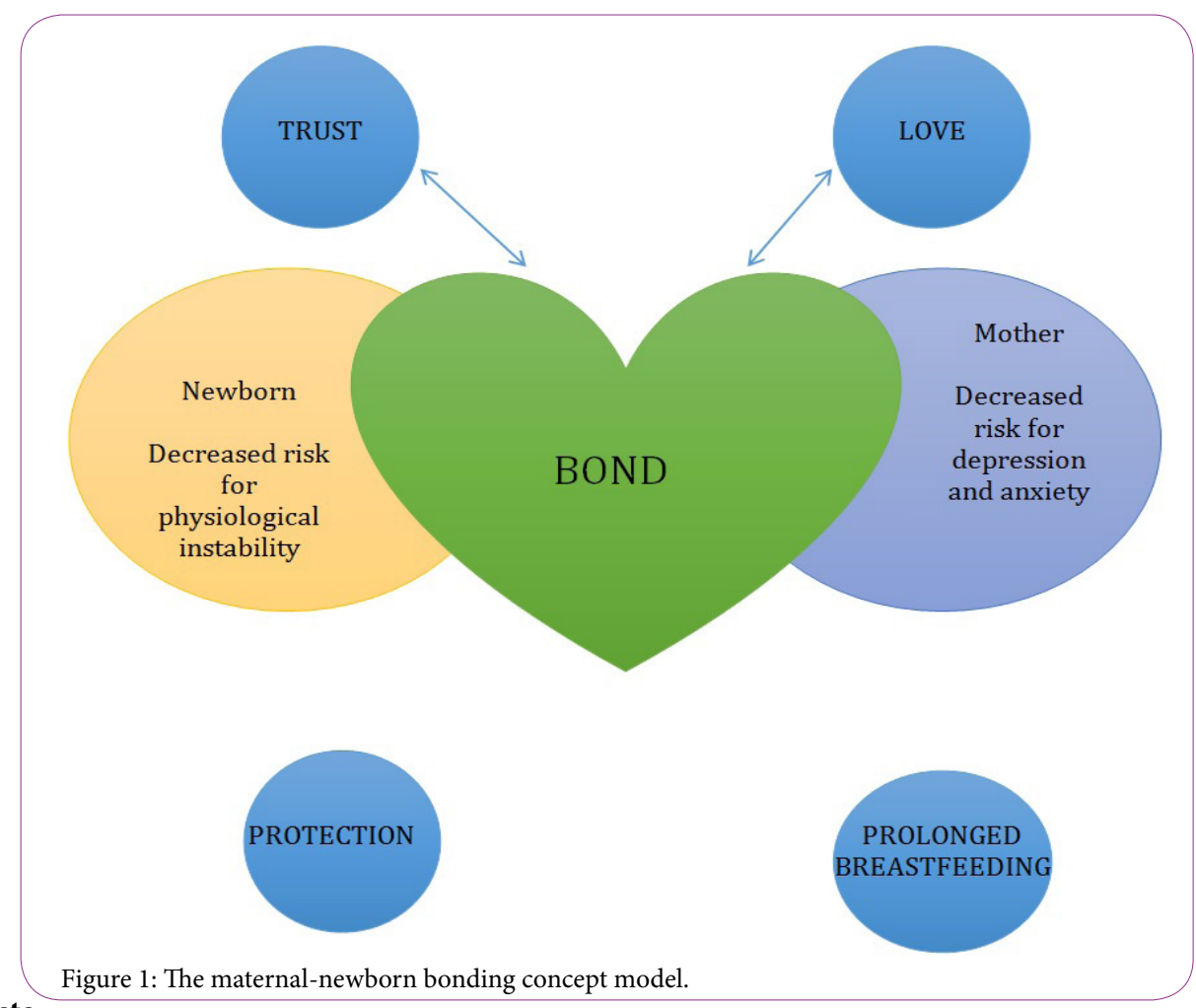

The authors declare that they have no competing interests.

\section{Funding}

This article was published with support from Texas Woman's University Libraries' Open Access Fund.

\section{References}

1. Spratt EG, Marsh C, Wahlquist AE, Papa CE, Nietert PJ, et al. (2016) Biologic effects of stress and bonding in mother-infant pairs. Int J Psychiatry Med 51: 246-257.

2. Ohoka H, Koide T, Goto S, Murase S, Kanai A, et al. (2014) Effects of maternal depressive symptomatology during pregnancy and the postpartum period on infant-mother attachment. Psychiatry Clin Neurosci 68: 631-639.

3. Walker LO \& Avant KC (2011) Strategies for Theory Construction in Nursing (5th edition).Upper Saddle River, New Jersey: Pearson Prentice Hall.

4. Altawell R, Roberts J (2010) Maternal-infant bonding. British Journal of Midwifery 18: 9.
13. Association (2016) In Oxford English Online Dictionary.

14. Relationship (2016) In Merriam-Webster's Online Dictionary.

15. Attachment (2016) In Cambridge English Online Dictionary.

16. Benoit D (2004) Infant-parent attachment: Definition, types, antecedents, measurement and outcome. Paediatr Child Health 9: 541-545.

17. Antecedent (2016) In Merriam-Webster's Online Dictionary.

18. Antecedent (2016) In Cambridge English Online Dictionary.

19. Conde-Agudelo A \& Díaz-Rossello JL (2016) Kangaroo mother care to reduce morbidity and mortality in low birthweight infants. Cochrane Database of Syst Rev 2000: CD002771.

20. Phillips R (2013) The sacred hour: Uninterrupted skin-to-skin contact immediately after birth. Newborn and Infant Nursing Reviews 13: 67-72.

21. Zetterström R (1999) Breastfeeding and infant-mother interaction. Acta Paediatr Suppl 88: 1-6.

22. Robson KS (1967) The role of eye-to-eye contact in maternal-infant attachment. Journal of Child Psychology and Psychiatry 8: 13-25. 
Citation: Barker J, Daniels A, O’Neal K, Van Sell SL (2017) Maternal-Newborn Bonding Concept Analysis. Int J Nurs Clin Pract 4: 229. doi: https://doi. org/10.15344/2394-4978/2017/229

23. DeCasper AJ, Fifer WP (1980) Of human bonding: Newborns prefer their mothers' voices. Science 208: 1174-1176.

24. Cernadas JM, Noceda G, Barrera L, Martinez AM, Garsd A (2003) Maternal and perinatal factors influencing the duration of exclusive breastfeeding during the first 6 months of life. J Hum Lact 19:136-144.

25. Taylor A, Atkins R, Kumar R, Adams D, Glover V (2005) A new mother-toinfant bonding scale: Links with early maternal mood. Arch Womens Ment Health 8: 45-51.

26. Cho E, Kim S, Kwon M, Cho H, Kim E, et al. (2016) The effects of kangaroo care in the neonatal intensive care unit on the physiological functions of preterm infants, maternal-infant attachment, and maternal stress. J Pediatr Nurs 31: 430-438.

27. American Academy of Pediatrics (2016) AAP policy on breastfeeding and use of human milk.

28. Wan M, Downey D, Strachan H, Elliott R, Williams S, et al. (2014) The neural basis of maternal bonding. PLos ONE 9: e88436.

29. Nonnenmacher N, Noe D, Ehrenthal JC, Reck C (2016) Postpartum bonding: The impact of maternal depression and adult attachment style. Arch Womens Ment Health 19: 927-935

30. Duber S, Reck C, Muller M, Gawlik S (2014) Postpartum bonding: The role of perinatal depression, anxiety, and maternal-fetal bonding during pregnancy. Arch Womens Ment Health 18: 187-195.

31. Kinsey CB, Baptiste-Roberts K, Zhu J, Kjerulff KH (2014) Birth-related, psychosocial, and emotional correlates of positive maternal-infant bonding in a cohort of first-time mothers. Midwifery 30: e188-e194.

32. Zanardo V, Soldera G, Volpe F, Giliberti L, Parotto M, et al.(2016) Influence of elective and emergency cesarean delivery on mother emotions and bonding. Early Human Development 99: 17-20. 